\title{
South African Archæology and Ethnology
}

$\mathrm{T}$ HE recent issue of the South African Journal of Science, vol. 31, contains several papers on archæology and ethnology read before the South African Association for the Advancement of Science at its meeting held at Port Elizabeth in July 1934 which are of more than local interest in their general bearing. Unfortunately, it is not possible here to do them full justice, and little more than a brief reference must suffice to direct attention to the more outstanding.

In his presidential address to Section E, Prof. L. F. Mainhard, of the University of the Witwatersrand, dealt with the linguistic approach to South African prehistory and ethnology, and after discussing the general principles upon which study of the morphology and vocabulary of a language may assist the ethnologist and prehistorian, applied these principles to the problem of the distribution and relations of Bushman, Hottentot and Bantu in the prehistory and early history of South Africa. A comparison of the Bushman and Hottentot tongues, as well as of the two click languages spoken in Central Tanganyika, points to a remote separation, long migration from north to south, followed by re-encounter of the two peoples, and at the same time supports the view of the school in physical anthropology, which maintains that the anatomical difference between Bushman and Hottentot is a fiction. On the other hand, the Hottentot distribution at the time of Bantu invasion and the continued oncoming of the Bantu from the sixteenth century, when the Portuguese recorded that they were already occupying the south-east coast, is to be inferred from place-names, while the cultural relations of the two sets of people are indicated in their loan-words. Loan-words relating to cattle and magic, for example, support this argument.

Among the archæological communications, that of Mr. John Hewitt describes a number of arrow-heads and barbs now in the Albany Museum, Grahamstown. Of these, some were recently discovered by Mrs. J. B. Meaker in the neighbourhood of Thaba 'Nchu, with other microliths, generally at the edges of dongas where pot-clay remains. These are pedunculate in form and of chalcedony or quartz. Two tanged arrow-heads discovered by Mr. H. J. Aitchison, also at Thaba 'Nchu, are of interest in view of the author's opinion that they lend support either to the view held by the Abbé Breuil that the tanged arrowhead is a contribution to South African culture of the northern neolithic of the proto-dynastic civilisation, or that it is a locally evolved derivation from uninfluenced Still Bay or Wilton.

Canon W. G. Sharples argues against the human origin of the so-called "Victoria West Implements" in dolerite, and demonstrates the production of implement-like forms in this material by purely natural causes.

An important paper by Dr. P. W. Laidler deals with the archæological and geological sequence in the Transkei and Ciskei. He points out that while it is probable that the stone age cultures of South Africa were less ancient than their European parallels, the absence of Pleistocene ice ages in South Africa deprives archæologists of the assistance they afford in Europe. There is, however, evidence in the Ciskei and Transkei of archæological relationship with pluvial periods which correspond with the phases of the ice age. As a result of the demonstration of the relation of deposits and types of industries on a number of sites, it is concluded that Stellenbosch occurred in a wet period, in which terrace gravels were laid down, possibly Gunz-Mindel, Riss-Wurm, while Fauresmith, now shown to be widely distributed and not restricted to the Free State, belongs to the gravels of a decreasing rainfall, a Levallois technique being present. This culture is shown to evolve from a late Stellenbosch and to pass into the Middle Stone Age, a graded series having been found on a site at Bonza Bay. The excavation of a Transkeian cave produced further evidence of the course of evolution of the Middle Stone Age, showing that high-backed, parallel flaked, lance-heads with revolved flaking preceded leaf-shaped secondarily worked blades. During the Middle Stone Age there was a further wet period, producing a layer of stalagmite in a cave where all rock is now dry, and possibly equating with Buhl. The leaf-points coincide with a dry period, while the Middle Stone Age closed with a period of seasonal rains. In the late Stone Age modern dry climate supervened.

In physical anthropology the skeletal structure of the Bushman naturally figures prominently. A symposium of members of the Department of Anatomy, University of the Witwatersrand, took place in which the physical characters of the Bushman were subjected to examination in detail. This is here reported in very full abstract, and inevitably will in future be regarded as a standard reference.

Before dealing with this communication, however, mention must be made of a report on human skeletal remains from East London, presented by Mr. L. H. Wells, of the Department of Anatomy, University of the Witwatersrand. The material was obtained by Dr. P. W. Laidler during his excavations on East London sites, and provides the physical anthropological counterpart of the archæological results. The remains fall into three groups. The 'Main Series' from various sites consists of eleven individuals, mostly of recent prehistoric age, the second group, the Quigney Sluit series, belongs to the period of European occupation and the third, the Cemetery series, comprises three skulls from a Bantu cemetery dated circa 1800-1870. As a general rosult, it is said that the heterogeneous character of the material points to the fundamental importance of adequate definition of ethnic types in South Africa. The presence of Bantu features in the more recent skeletons is the physical counterpart of Maingard's historical data of the infiltration of the Bush population of this area by a Bantu element; and the predominantly Bush-Boskopoid character of the Cemetery series is striking evidence of the persistence of this ancient type, despite subsequent changes in the population.

The symposium on the "Skeleton of the Bush Race" consists of eight communications, each dealing with some specific investigation based on known Bush material, partly from the McGregor Memorial Museum, partly from the anthropological collection of the Department of Anatomy at the University of the Witwatersrand. The points covered include the skull, mandible, dentition, shoulder girdle and upper limb, vertebral column, sacrum and lower limb. So far as the detailed results here recorded may be reduced to any general principle, it is that they point to the Bush type being highly evolved, but at the same time much specialised. Thus in 
relation to the calvaria, it is pointed out that an examination of curvatures of the crania show that the Bushman occupies a higher evolutionary place than Cro-Magnon man, and according to one method of study even a higher rung than the European. This latter result, however, is due to the employment of a method which as a measure of fœtalisation points to an extreme specialisation rather than a high status in evolutionary development. In the examination of the pelvis, by Miss Margaret Orford, the results point to the similar indication of specialisation. She concludes that the Bush pelvis is primitive or apelike in many respects; and on the whole the Bush female pelvis exhibits primitive characteristics in more exaggerated form than does the male. The bones are small in absolute measurement, but massive in proportion to their size. The sex differences are well-marked. The Bush pelvis was capable of developing secondary specialisations, such as the exaggerated features of sexual differentiation, the shallow acetabulum, etc. It is, therefore, an intimate admixture of primitive and specialised features.

\section{Systems of Economic Reform}

$\mathrm{D}^{\mathrm{u}}$ URING recent years, men in all walks of life have begun to question the present structure of society with its apparently inevitable liability to periodic maladjustments, and in an endeavour to suggest a remedy of present ills, all kinds of proposals have been put forward. The very multiplicity of these plans for economic betterment, however, is bewildering and confusing, even to those who have the time to examine them in some detail. For this reason alone the recent publication by the Engineers' Study Group on Economics of a chart analysing in convenient form the salient features of fourteen different proposals for economic reform should serve a useful purpose. In addition to this chart, the Group, which was formed by a number of engineers and men of science somewhat more than a year ago, has recently prepared a valuable interim report* which examines twenty-four separate sets of proposals, analysing them under three headings, namely, $(a)$ monetary, $(b)$ industrial planning and $(c)$ a combination of industrial planning and monetary. The real division of opinion which this classification is intended to emphasise is that existing between those who think that prosperity can be reached by alterations, radical or otherwise, in the monetary system, and those who believe that some control of industrial production is required. The division is also of importance in respect of immediate practical possibilities. Few if any of the monetary proposals would require elaborate preliminaries, and most of them could be brought into full operation in a comparatively short time. It is otherwise with the schemes which involve planning, as these would almost invariably take time to put into practice.

Most of those who make proposals for economic reforms start with an analysis of the present situation, and there is a considerable difference of opinion as to the main causes of the position, though there is a measure of agreement among certain groups of schemes. Several of the proposals for monetary reform definitely assert that insufficient purchasing power is at present distributed to purchase the goods which are being produced. The supporters of the Consumer Money League and of the Social Credit Scheme of Major Douglas assert that this deficiency is automatic and inevitable; accordingly the Consumer Money League advocates local note issues, while the Douglas proposals suggest remedying the deficiency either by issuing credit to retailers conditionally on sales at regulated prices, or by way of a 'national dividend' to every individual.

* The British Science Guild : Engineers' Study Group on Economics. First Interim Report on Schemes and Proposals for Economic and Social Reforms. Pp. 44. (London: British Science Guild, 6 John Hazlitt House, Chancery Lane, W.C.1: 1935.) 18.
In the opinion of Mr. J. M. Keynes, the deficiency of purchasing power is not necessarily permanent, and his immediate remedy for the present situation is large-scale public works, financed by Government loans. The London Chamber of Commerce suggests the monetisation of commodities by issuing currency against eligible trade bills. Silvio Gesell's 'Demurrage Money' scheme, which involves the elimination of interest, and the Kearney 'True Finance' scheme also assert that there is insufficient purchasing power, but their main remedy is designed to correct this shortage by increasing the velocity of circulation rather than the amount of money.

Two more schemes, those of Lord Melchett and Prof. F. Soddy, diagnose a shortage of effective purchasing power, but do so somewhat less definitely than is the case with the other schemes previously mentioned. Lord Melchett proposes to meet the apparent shortage by monetisation of commodities and by paying off the National Debt by means of bank drafts. Prof. Soddy holds that the shortage is due to the fact that it is to the interest of the bankers who control the issue of money to keep it scarce, and he therefore advocates the nationalisation of the issue of currency and credit and the control of such issues by a scientifically determined price index.

The three remaining monetary schemes examined in the report, namely, those of McGregor, Deane and Sir Basil Blackett, stress lack of balance as being mainly responsible for the present situation. The McGregor plan defines balance as that between spending and saving, and holds that the existing situation is due to over-saving and that it can be rectified by raising or lowering the general salary and wage level by carefully calculated percentages. The Deane plan, which is American in origin, stresses mal. distribution of purchasing power resulting from technological unemployment as the root of the trouble and accordingly proposes a special kind of unemployment insurance. Sir Basil Blackett suggests, in his "Planned Money", that the lack of balance is more general and requires to be remedied by a currency based on a price index and managed with the view of maintaining stable prices. He also commends planning and co-ordination.

The next group of schemes arraigns unco-ordinated individualism as largely responsible for the present troubles. The schemes can conveniently be analysed into two sections, namely :

(a) Mr. Harold Macmillan's "Reconstruction" proposal, Fascism, the 'New Deal' in the United States, and the schemes of the 'New Britain' Group and of the 'Political and Economic Planning' Group.

(b) H. S. Jevons's 'Credit Income System', Communism, Technocracy, the programmes of the Labour 